\title{
NOTE
}

\section{Validation of otolith daily increments in the tropical eel Anguilla marmorata}

\author{
Hagi Yulia Sugeha ${ }^{*}$, Akira Shinoda, Miho Marui, Takaomi Arai ${ }^{* *}$, Katsumi Tsukamoto \\ Ocean Research Institute, The University of Tokyo, Minamidai, Nakano Tokyo 164-8639, Japan
}

\begin{abstract}
To determine the periodicity of the deposition of growth increments in the otolith of the glass eels of the tropical eel Anguilla marmorata, an otolith validation experiment was performed. Glass eels were captured at the mouth of the Poigar River, north Sulawesi Island, Indonesia, and then immersed in an alizarin complexone (ALC) solution to mark their otoliths. After being held under natural conditions in the river for $20 \mathrm{~d}$, it was found that the number of rings outside the ALC mark was $20.1 \pm 0.7$ (mean \pm SD), which coincided with the number of days after the ALC treatment. This validation experiment indicated that the growth increments in the otoliths of A. marmorata glass eels were deposited daily and can be used for daily age determination.
\end{abstract}

KEY WORDS: Anguilla marmorata $\cdot$ Otolith · Daily increment ALC mark · Daily ring $\cdot$ Tropical eel

Resale or republication not permitted without written consent of the publisher

Many recent studies have used the examination of the otoliths microstructure and microchemistry of glass eels or leptocephali to learn about the early life history of the temperate eel Anguilla japonica (Tabeta et al. 1987, Tsukamoto \& Umezawa 1990, Cheng \& Tzeng 1996, Arai et al. 1997), A. rostrata (Wang \& Tzeng 1998, Arai et al. 2000b), A. anguilla (Castonguay 1987, LecomteFiniger 1992, Arai et al. 2000b), A. australis (Arai et al. 1999d, Marui et al. 2001), and A. dieffenbachii (Marui et al. 2001). Otolith studies on tropical eels have been done with A. bicolor pacifica, (Arai et al. 1999b, 2001a,b, Marui et al. 2001), A. celebesensis (Arai et al. 1999c, 2001b, Marui et al. 2001), and A. marmorata (Budimawan 1997, Arai et al. 1999c, 2001a,b, Marui et al. 2001). However, most of the studies have been done

\footnotetext{
${ }^{*}$ E-mail: yuli@ori.u-tokyo.ac.jp

** Present address: Otsuchi Marine Research Center, Ocean Research Institute, The University of Tokyo, 2-106-1, Akahama, Otsuchi, Iwate 028-1102, Japan
}

based on the assumption of daily periodicity of otolith growth increment deposition, although reliable validation studies on the deposition of otolith increment has been done only in the 2 temperate species $A$. japonica (Tsukamoto 1989) and A. rostrata (Martin 1995), as well as in the tropical species $A$. celebesensis (Arai et al. 2000a).

The tropical eel Anguilla marmorata is the most widely distributed anguillid species in the world, but relatively little is known about most aspects of its life history. Some studies have been conducted on A. marmorata that were related to the geographical distribution (Ege 1939, Jespersen 1942), population structure (Ishikawa 1998), possible spawning grounds and time of spawning (Jespersen 1942, Budimawan 1997, Aoyama et al. 1999, Arai et al. 2001a), distribution and dispersal (Aoyama et al. 1999, Arai et al. 2001a) and inshore migration (Arai 2000, Arai et al. 1999a, Sugeha et al. in press). Further studies on the early life history of A. marmorata from the Indo-Pacific have been conducted on glass eel otolith microstructure (Budimawan 1997, Arai et al. 1999c, 2001b, Marui et al. 2001) and microchemistry (Arai et al 1999c, 2001a,b, Marui et al 2001). In those studies, the authors analyzed the early life history parameters of $A$. marmorata such as backcalculating the hatching date, the age at first feeding, the duration of leptocephalus stage, metamorphosis, and the oceanic glass eel stage, as well as the age at recruitment. However, prior to the present study, the validation of the daily deposition of the otolith growth increments of $A$. marmorata had not been done, and was assumed to be daily based on studies with other anguillid species.

The objective of the present study was to validate the daily deposition of the growth increments in the otoliths of Anguilla marmorata using an Alizarin complexone (ALC) marking technique. 
Materials and methods. Glass eels were collected at night $(02: 00$ to $04: 00 \mathrm{~h})$ in the mouth of the Poigar River, north Sulawesi Island, Indonesia, on June 3, 2000 , using triangular scoop nets $\left(0.3 \mathrm{~m}^{2}\right.$ mouth, $1 \mathrm{~mm}$ mesh). At that time, all specimens were at the VA or VB stage of development of pigmentation, referred to as the glass eel stage. Specimens were kept in a basket with water taken from the sampling site $\left(24\right.$ to $\left.25^{\circ} \mathrm{C}\right)$ for approximately $3 \mathrm{~h}$ (3 $\mathrm{g}$ fish $\left.\mathrm{l}^{-1}\right)$, before being treated with an otolith marking method as in Tsukamoto (1985, 1988). Fish were transferred into a 201 aquarium containing a $100 \mathrm{mg} \mathrm{l}^{-1}$ solution of alizarin complexone (ALC) in well water and held there for $24 \mathrm{~h}$ (Arai et al. 2000a). The aquarium remained in the shade throughout this period, during which ambient temperatures ranged from 24 to $26^{\circ} \mathrm{C}$.
After ALC treatment, the specimens were placed in a $50 \times 50 \times 50 \mathrm{~cm}$ net cage consisting of $1 \mathrm{~mm}$ mesh. The cage was then immersed underwater in a branch of the Poigar River near the sampling site to a depth of approximately $25 \mathrm{~cm}$ below the surface and about $100 \mathrm{~cm}$ from the bottom, where they experienced ambient daily environmental conditions and tidal influences throughout the experiment. Temperature and salinity were measured every $2 \mathrm{~h}$ during the $20 \mathrm{~d}$ experiment. All of the specimens were removed from cage after $20 \mathrm{~d}$ (June 24, 2000) and preserved in $99 \%$ ethanol.

Body length measurements were done to the nearest $0.1 \mathrm{~mm}$ and pigmentation was observed as according to Bertin (1956). Following Arai et al. (1999a) and Sugeha et al. (in press); all specimens were identified on the basis of their external morphology. Of these, 30 of the speci-

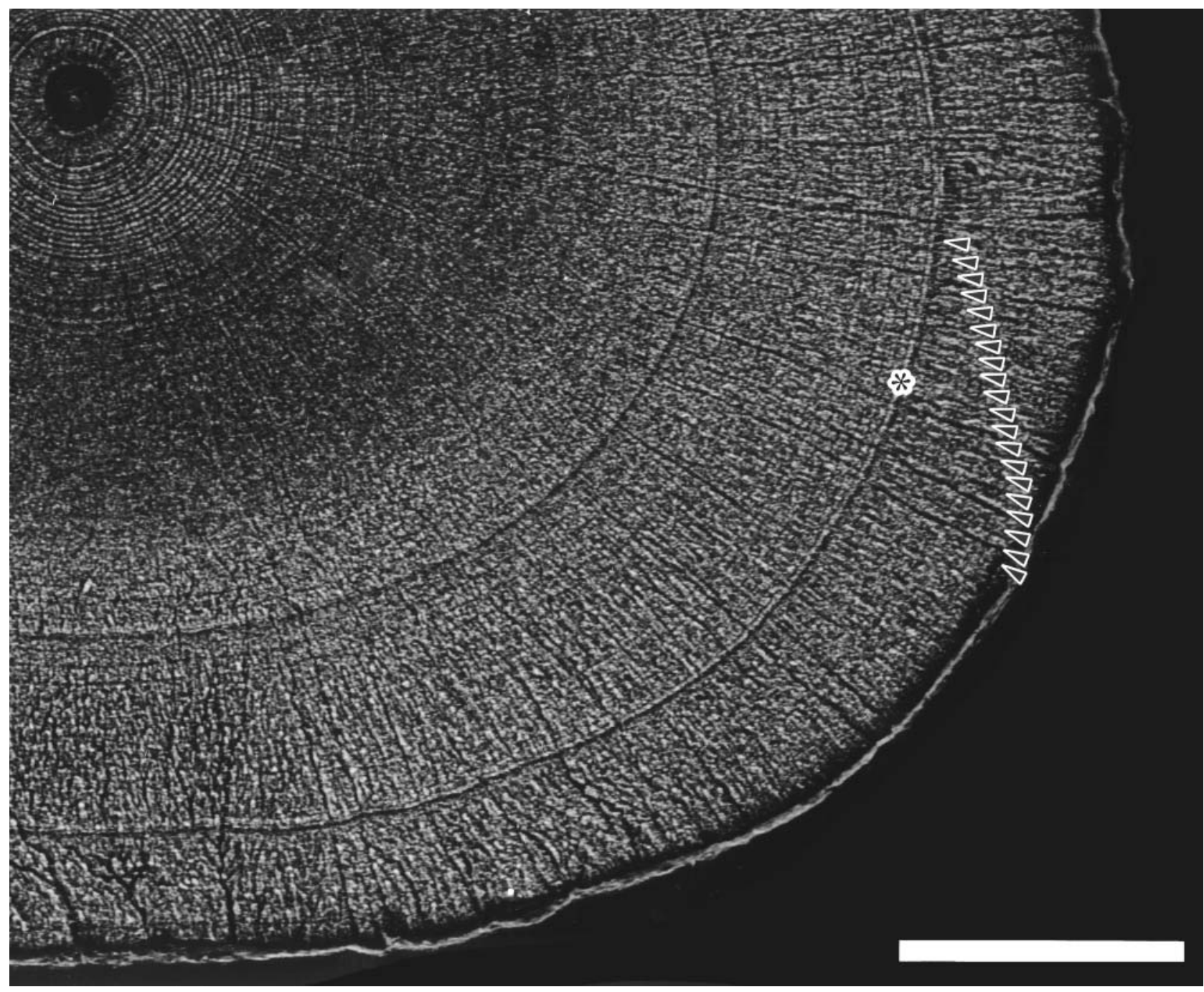

Fig. 1. SEM photograph in the sagittal otolith of Anguilla marmorata glass eel (TL $47.50 \mathrm{~mm}$ ) by time marking with alizarin complexone (ALC) solution (Scale: $50 \mu \mathrm{m}$ ). The arrow indicates all of the 20 increments rings outside ALC mark and the asterisk indicates the check pattern corresponding to red fluorescent mark due to ALC treatment 
mens identified as Anguilla marmorata were used for otolith analysis in the validation study. Sagittal otolith were extracted from each fish and embedded in epoxy resin (Epofix; Struers, Copenhagen, Denmark). The otoliths were then ground to expose the core, using a grinding machine equipped with a diamond cup wheel (Discoplan-TS; Struers), and further polished with 6 and $1 \mu \mathrm{m}$ diamond paste on an automated polishing wheel (Planopol-V; Struers). After they were polished, otolith samples were etched with $0.05 \mathrm{M} \mathrm{HCl}$ for 10 to $30 \mathrm{~s}$.

A red fluorescent mark resulting from ALC treatment was located with the use of a light microscope equipped with an ultraviolet (UV) light source as described by Tsukamoto $(1985,1988)$. This red ALC mark was further examined using scanning electron microscopy (SEM) and was visible as a slight check pattern (Fig. 1). The presence and location of the fluorescent ALC mark on each otolith were confirmed under UV light, and a total of 21 specimens with a clear red fluorescent mark were examined to verify deposition rate of otolith increments. The increments outside the ALC mark were counted using SEM photographs at $1500 \times$ magnification.

Results and discussion. Anguilla marmorata glass eels were successfully marked with an alizarin complexone (ALC) solution. They were then held for $20 \mathrm{~d}$ in water in the Poigar River estuary that ranged from 24 to $30^{\circ} \mathrm{C}$ and 9.4 to $9.8 \%$ in water temperature and salinity, respectively.

At the end of the $20 \mathrm{~d}$ experiment, the average total length of all specimens was $48.9 \pm 1.0 \mathrm{~mm}$ with a range from 47.5 to $50.0 \mathrm{~mm}$ ). The degree of development of their pigmentation patterns was more advanced and belonged to stage VIAiv, which is defined as the elver stage. Clear concentric rings (increments) could be observed from the core to the edge using SEM examination (Fig. 1). A distinct red mark of ALC was detected in the otolith of 21 of the individuals examined. A checked, heavy discontinuous zone, was observed with normal light that corresponded to the ALC mark observed with UV light. The average number of increments between this ALC mark (a check pattern) and the edge of the otolith was $20.1 \pm 0.7$ ranging from 19 to 21 (Fig. 2). The number of increments outside the ALC mark in the otolith were not significantly different from the expected values of 20 increments ( $p>0.5$, MannWhitney $U$-test). The average of 20.1 increments coincided with the number of days of the holding period after the ALC treatment $(20 \mathrm{~d})$. This indicated that the increments observed in the sagittal otoliths of the glass eels or early stage elvers were deposited daily.

In the present study, the daily deposition of otolith increments in late stage glass eels and elvers was confirmed for the tropical eel Anguilla marmorata. This suggests that the otolith increments of $A$. marmorata can be used for precise daily age determination in this species if the pattern of ring formation is the same throughout the early life history period. Tsukamoto (1989) found a slightly lower average number of increments outside a tetracycline (TC) mark than the actual number of days in a $40 \mathrm{~d}$ laboratory experiment with $A$. japonica glass eels, namely $38.6 \pm 2.9$ ranging from 31 to 43. In A. rostrata glass eels, Martin (1995) found that the average number of increments outside the tetracycline mark was $9.64 \pm 0.14$ and $19.13 \pm 0.16$, with a range of 8 to 11 and 18 to 21 increments in 10 and $20 \mathrm{~d}$ field experiments, respectively. In A. celebesensis, the range of number of increments outside the ALC mark was 8 to 11 in $10 \mathrm{~d}$, and 17 to 22 in $20 \mathrm{~d}$ field experiments, with average number of increments being $9.4 \pm$ 0.9 and $19.4 \pm 1.4$, respectively (Arai et al. 2000a). All these studies showed a slightly smaller numbers of average otolith growth increments than the number of days of each experimental period.

In the present study, however, the mean number of increments outside the ALC mark in Anguilla marmorata was 20.1 with a range from 19 to 21 for the $20 \mathrm{~d}$ field experiment. The discrepancy in averages and ranges of numbers of increments between previous studies and the present study could be due to differences in experimental conditions such as water quality, temperature, salinity, and food availability between laboratory and field experiments. The present study should be more realistic than the previous studies because we held the fish in their natural environment during the experimental period. The others' studies were done in the laboratory, where conditions may be more stressful for the glass eels and may result in a lack of deposition of several rings. Another factor that may contribute to variation between the number of otolith increments and the number of days since marking, is the potential for counting errors at the outermost few increments at the otolith edge, which typically are

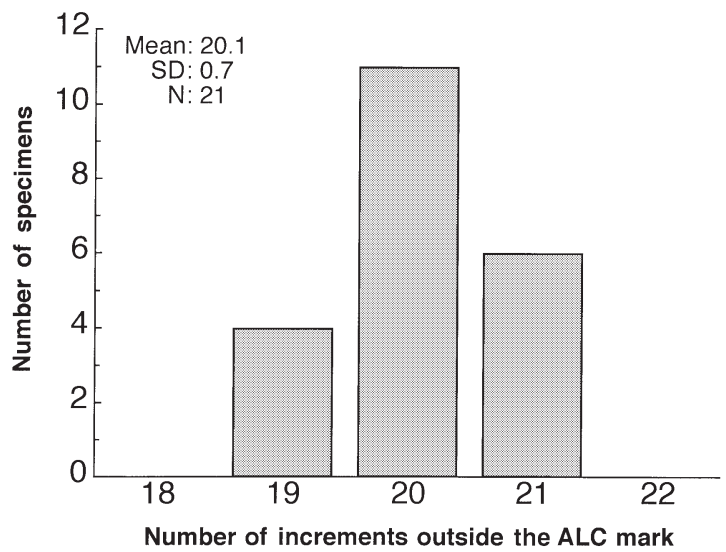

Fig. 2. Frequency distribution of the numbers of increments outside the ALC mark in the sagittal otolith of Anguilla marmorata glass eels in a $20 \mathrm{~d}$ experiment 
not well defined (Arai et al. 2000a). However, the difference between the results of these validation studies is not very large and they all suggest that anguillid fish deposit otolith rings daily.

Acknowledgements. We thank Dr D. Limbong for cooperation in preparing the field experiment, Dr M. J. Miller for critically reading the manuscripts, and $\mathrm{M}$. Oya for her assistance in many aspects of the project. This work was supported in part by Grants-in-Aid No. 07306022, 07556046, 08041139 and 08456094 from the Ministry of Education, Science, Sports and Culture, Japan; Research for the Future Program No. JSPSRFTF 97L00901 from the Japan Society for the Promotion of Science; Eel Research Foundation from Nobori-kai; the Research Foundation from Touwa Shokukin Shinkoukai. Partial support was also given to H.Y.S. in the form of a Monbusho Foreign Student Scholarship from the Ministry of Education, Science, Sports and Culture, Japan.

\section{LITERATURE CITED}

Aoyama J, Mochioka N, Otake T, Ishikawa S, Kawakami Y, Castle P, Nishida M, Tsukamoto K (1999) Distribution and dispersal of anguillid leptocephali in the western Pacific Ocean revealed by molecular analysis. Mar Ecol Prog Ser 188:193-200

Arai T (2000) Ecological study on the inshore migration of the eels, Anguilla spp. in Sulawesi Island. PhD thesis, University of Tokyo

Arai T, Otake T, Tsukamoto K (1997) Drastic changes in otolith microstructure and microchemistry accompanying the onset of metamorphosis in the Japanese eel Anguilla japonica. Mar Ecol Prog Ser 16:17-22

Arai T, Aoyama J, Limbong D, Tsukamoto K (1999a) Species composition and inshore migration of tropical eels, Anguilla spp., recruiting to the estuary of the Poigar River, Sulawesi Island. Mar Ecol Prog Ser 188:299-303

Arai T, Otake T, Limbong D, Tsukamoto K (1999b) Early life history and recruitment of the tropical eel, Anguilla bicolor pacifica, as revealed by otolith microstructure and microchemistry. Mar Biol 133:319-326

Arai T, Limbong D, Otake T, Tsukamoto K (1999c) Metamorphosis and inshore migration of tropical eels Anguilla spp. in the Indo-Pacific. Mar Ecol Prog Ser 182:283-293

Arai T, Otake T, Jellyman DJ, Tsukamoto K (1999d) Differences in the early life history of the Australasian shortfinned eel, Anguilla australis from Australia and New Zealand, as revealed by otolith microstructure and microchemistry. Mar Biol 135:381-389

Arai T, Limbong D, Tsukamoto K (2000a) Validation of otolith daily increments in the tropical eel Anguilla celebesensis. Can J Zool 78:1078-1084

Arai T, Otake T, Tsukamoto K (2000b) Timing of metamorphosis and larval segregation of the Atlantic eels, Anguilla rostrata and $A$. anguilla, as revealed by otolith microstructure and microchemistry. Mar Biol 137:39-45

Arai T, Aoyama J, Ishikawa S, Miller MJ, Otake T, Inagaki T,

Editorial responsibility: Otto Kinne (Editor), Oldendorf/Luhe, Germany
Tsukamoto K (2001a) Early life history of tropical Anguilla leptocephali in the western Pacific Ocean. Mar Biol 138: 887-895

Arai T, Limbong D, Otake T, Tsukamoto K (2001b) Recruitment mechanisms of tropical eels, Anguilla spp. and implications for the evolution of oceanic migration in the genus Anguilla. Mar Ecol Prog Ser 216:253-264

Bertin L (1956) Eels - a biological study. Cleaver-Hume Press, London

Budimawan (1997) The early life history of the tropical eel Anguilla marmorata (Quoy and Gaimard 1824) from four Pacific estuaries, as revealed from otolith microstructural analysis. J Appl Ichthyol 13:57-62

Castonguay M (1987) Growth of American and European eel leptocephali as revealed by otolith microstructure. Can J Zool 65:875-878

Cheng PW, Tzeng WN (1996) Timing of metamorphosis and estuarine arrival across the dispersal range of the Japanese eel Anguilla japonica. Mar Ecol Prog Ser 131:87-96

Ege V (1939) A revision of the genus Anguilla Shaw: A systematic, phylogenetic and geographycal study. Dana-Rep 16:1-256

Ishikawa S (1998) Molecular study on the population structure of Anguilla marmorata. $\mathrm{PhD}$ thesis, University of Tokyo

Jespersen P (1942) Indo-Pacific leptocephali of the genus Anguilla. Dana-Rep 22:1-128

Lecomte-Finiger R (1992) Growth history and age at recruitment of European glass eels (Anguilla anguilla) as revealed by otolith microstructure. Mar Biol 114:205-210

Martin MH (1995) Validation of daily growth increments in otoliths of Anguilla rostrata (Lesueur) elvers. Can J Zool 73:208-211

Marui M, Arai T, Miller MJ, Jellyman DJ, Tsukamoto K (2001) Comparison of early life history between New Zealand temperate eels and Pacific tropical eels revealed by otolith microstructure and microchemistry. Mar Ecol Prog Ser 213:273-284

Sugeha HY, Arai T, Miller MJ, Limbong D, Tsukamoto K (2001) Inshore migration of the tropical eels, Anguilla spp. recruiting to the Poigar River estuary on north Sulawesi Island. Mar Ecol Prog Ser 221 (in press)

Tabeta O, Tanaka K, Yamada J, Tzeng WN (1987) Aspects of the early life history of the Japanese eel Anguilla japonica determined from otolith microstructure. Bull Jpn Soc Sci Fish 53:1727-1734

Tsukamoto K (1985) Mass-marking of ayu eggs and larvae by Tetracycline-tagging of otoliths. Bull Jpn Soc Sci Fish 51: 903-911

Tsukamoto K (1988) Otolith tagging of ayu embryo with fluorescent substances. Bull Jpn Soc Sci Fish 54:1289-1295

Tsukamoto K (1989) Otolith daily growth increments in the Japanese eel. Bull Jpn Soc Sci Fish 55:1017-1021

Tsukamoto K, Umezawa A (1990) Early life history and oceanic migration of the eel, Anguilla japonica. La Mer 28:188-198

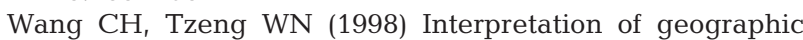
variation in size of American eel Anguilla rostrata elvers on the Atlantic coast of North America using their life history and otolith ageing. Mar Ecol Prog Ser 168:35-43

Submitted: April 11, 2001; Accepted: June 12, 2001

Proofs received from author(s): September 4, 2001 